\title{
Teresa de la Parra e Ifigenia (1924): Mujer y escritura
}

\author{
Teresa de la Parra and Iphigenia (1924): Woman and Writing
} Teresa de la Parra e Ifigênia (1924): mulher e escritora

Froilán Ramos Rodríguez ${ }^{1}$

\section{Resumen}

Este ensayo analiza la presencia de rasgos autobiográficos de Teresa de la Parra (1889-1936) en su obra Ifigenia. Diario de una señorita que escribió porque se fastidiaba (1924), uno de los pocos casos de una mujer escritora latinoamericana en los años veinte. Se profundiza en tres aspectos: 1. La formación intelectual y trayectoria literaria de la autora; 2. La descripción de la dama protagonista de la novela, María Eugenia Alonso; y 3. La relación de Teresa de la Parra y la imagen de la mujer educada a través del personaje de María Eugenia. En suma, desde una perspectiva histórica, la obra Ifigenia, y su propia creadora, representan un testimonio de la literatura sobre la comprensión de una parte de las mujeres latinoamericanas que tuvieron acceso a la educación, a principios de la vigésima centuria.

Palabras claves: Teresa de la Parra, Ifigenia, mujer, escritura.

\section{Abstract}

This paper analyzes the presence of autobiographical traits from Teresa de la Parra (1889-1936) in the book Iphigenia. Diary of a young lady who wrote because she was annoyed (1924), as one of the few cases of Latin American women writers in the twentieth century. In this regard, it explores three aspects: 1 . The intellectual development and literary career of the author; 2 . The description of the female protagonist of the novel, Maria Eugenia Alonso; and 3. The relationship of Teresa de la Parra and image of the woman educated through the character of Maria Eugenia. To conclude from a historical perspective, the book Iphigenia, and its creator, represents a testimony of literature, promoting a clearer understanding of Latin American women, who had access to education, during the early twentieth century.

Keywords: Teresa de la Parra, Iphigenia, woman, writing.

\section{Resumo}

Este ensaio analisa a presença de rasgos autobiográficos de Teresa de la Parra (1889-1936) em sua obra Ifigênia. 0 diário duma senhorita que escreveu por que ela se incomodava (1924), um dos poucos casos duma mulher escritora latino-americana nos anos vinte. Aprofundase em três aspetos: 1. A formação intelectual e trajetória literária da autora; 2. A descrição da dama protagonista da novela, Maria Eugenia Alonso; e 3. A relação de Teresa de la Parra e a imagem da mulher educada através do personagem de Maria Eugenia. Em suma, desde a perspectiva histórica, a obra Ifigênia, e sua própria criadora, representam um testemunho da literatura sob a compreensão de uma parte das mulheres latino-americanas, que tiveram aceso à educação, a princípios da vigésima centúria.

Palavras-chaves: Teresa de la Parra, Ifigênia, mulher, escritura.

Artículo recibido el 19 de noviembre de 2014 y aprobado el 26 de junio de 2015

1 Universidad Simón Bolívar, Caracas, Venezuela. Universidad de los Andes, Santiago, Chile. Correo electrónico: froilanr@usb. ve,fjramos2@miuandes.cl 
Muy halagada me tendría el comprobar su predilección por mí sobre Teresa de la Parra, [...] Me duele apagar a una rival y siento por la pretendida autora de esa nueva "Ifigenia" cierta amistad sincera, donde se mezclan cordialmente la compasión, el desdén y la simpatía. En el fondo no puedo decir que la desprecio.

María Eugenia Alonso ${ }^{2}$

\section{Introito}

Ifigenia. Diario de una señorita que escribió porque se fastidiaba (1924) fue la primera novela de la escritora venezolana Teresa de la Parra (1889-1936), en la cual recogió las vivencias de María Eugenia Alonso, joven educada en Europa en medio del refinamiento y los progresos de todo tipo, que regresa a Venezuela, a una sociedad todavía apegada a costumbres del siglo XIX, lo que producirá un choque entre los dos mundos que se contraponen en la novela dama: por un lado, el de sus anhelos y lo que había observado en el Viejo Continente y, por el otro, el de las conductas tradicionales y el matrimonio arreglado que terminará aceptando, con cierta resignación.

Más allá de la valoración literaria de la novela Ifigenia y del legado narrativo de su autora, la obra en sí misma y la propia Teresa de la Parra representan el testimonio de una época, en la que se recoge la imagen descriptiva de una parte de la mujer en la sociedad venezolana de los años veinte, pero también, y quizá más importante aún, visto con ojos femeninos; lo cual no deja de ser para el historiador una oportunidad de ahondar en el mundo interior del pensamiento y aspiraciones de la mujer latinoamericana de inicios del siglo $\mathrm{xx}$.

\section{La Creadora. Formación intelectual de Teresa de la Parra (1889-1936)}

El París de 1889 era la ciudad luz que irradiaba sus destellos de brillo al otro lado del Atlántico, eclipsaba los ojos americanos, y les atraía como centro

2 Carta firmada por María Eugenia Alonso, en 1926, dirigida a don Lisandro Alvarado (Parra, 1982, p. 566). intelectual, artístico y cultural del mundo latino. Mientras en Europa se conservaba la paz gracias al sistema de Bismarck, en la capital francesa se desarrollaba la Exposición Mundial, cuyo símbolo más elevado fue la Torre Eiffel. En esta ciudad nació Ana Teresa del Rosario Parra Sanojo ${ }^{3}$ el 5 de octubre de 1889. Fue la primera de las hijas, de don Rafael Parra Hernáiz, cónsul venezolano en Berlín, y doña Isabel Sanojo Ezpelosín. Ambos provenían de familias tradicionales venezolanas ${ }^{4}$, y se hallaban circunstancialmente en Francia debido a las labores diplomáticas del padre.

Junto con los cambios políticos ocurridos en Venezuela, luego de la separación definitiva de Antonio Guzmán Blanco del poder, en 1888, comenzó también el término de la carrera diplomática del padre. Hacia 1891, la familia Parra Sanojo regresó a Venezuela, se instalaron en la Hacienda de Tazón, dedicada al cultivo de caña de azúcar, al suroeste de Caracas. En medio del ambiente del campo, transcurrieron los primeros años de la niña Ana Teresa, junto con sus dos hermanos mayores, Miguel y Luis Felipe, y sus tres hermanas menores, Isabel, Elia y María.

Estos años, de 1891 a 1899, son los años de juego de Ana Teresa, cuya primera instrucción quedó al cuidado de una preceptora contratada, que le enseñó a ella y sus hermanas a leer, escribir, contar y recitar fabulas en francés, al tiempo que pudo desarrollar actividades campestres de la hacienda. En fecha no determinada con exactitud, probablemente hacia 1899, luego del fallecimiento del padre, y aunado a los cambios políticos en el país, con la llegada de los andinos al poder, la familia se trasladó a España (Bosch, "Cronología", en Parra, 1982, p. 648) donde tenían parientes maternos, los Sanojo del Llano. Doña Isabel y sus hijos se establecieron en Godella, una pequeña población cercana a Valencia.

3 De los trabajos biográficos sobre Teresa de la Parra, sobresalen los de Díaz Sánchez, por haberla conocido en vida y ser el primero en publicarlo. Pueden consultarse: Díaz Sánchez, 1954; Bosch, 1979; Lemaitre, 1987.

4 Del lado paterno descendían del general Carlos Soublette y Jerez de Aristiguieta, del lado materno descendían del doctor Luis María Sanojo, y a su vez del Conde de Tovar (Palacios, 2005, p. 31). 
Ana Teresa fue internada en el Colegio del Sacré Coeur (Palacios, 2005, pp. 36-37), un instituto educativo dirigido por las religiosas del Sagrado Corazón de Jesús. En el Boletín del Sagrado Corazón, agosto de 1908, aparecieron versos de Ana Teresa, con los que obtuvo el primer premio escolar, el día de la Beatificación de la Madre Magdalena Sofía Barat (1779-1865), fundadora de la Sociedad del Sagrado Corazón de Jesús. En estos años fue una disciplinada, aplicada y sobresaliente alumna.

Ya en su adolescencia, Ana Teresa aprendió el idioma francés, y llegó a dominarlo con soltura y naturalidad, lengua que conservó en pleno uso a lo largo de su vida. También leyó a los maestros españoles, Miguel de Cervantes, Santa Teresa de Jesús, San Francisco; fue formando un fuerte hábito por la lectura, el aprecio a los libros, y la disciplina de elegir sus propios autores, lo que le permitió edificar una nutrida cultura universal a través de obras clásicas, de sus años en España, y viaje a Francia.

En 1909, Ana Teresa retornó a Venezuela, residió la mayor parte de su estadía en Caracas, hasta 1923. Para entonces, Venezuela era una nación exportadora de café, con una incipiente extracción de hidrocarburos; un país predominantemente rural, gobernado desde 1908 por Juan Vicente Gómez ${ }^{5}$, quien instauró una dictadura pretoriana personalista (prolongada hasta 1935). La capital todavía conservaba arquitectura de estilo colonial, con sus casas de techos de ladrillos y los edificios del neoclásico francés levantados en el último cuarto del siglo anterior.

Durante este periodo de 1909 a 1923, pasó de su primera juventud a ser una dama eternamente hermosa y elegante. Dedicaba la mayor parte de su tiempo a la lectura, gustaba del cine y del teatro (Palacios 2005, p. 46), y, ocasionalmente, cuando podía, realizaba visitas al campo. Fue una etapa en la que sus hermanas se casaron, mientras ella permaneció soltera por voluntad propia. En la cuidad de Ávila, la escritora conoció a doña Emilia Ibarra Urbaneja y Rodríguez del Toro, proveniente de una de las familias de más larga tradición y riqueza, con

5 Puede consultarse: Pino Iturrieta, 1988 la cual compartía el gusto por la cultura, la tertulia y la curiosidad intelectual, lo que llevó a ambas mujeres a hacerse amigas muy cercanas.

Para 1915, Ana Teresa viajó nuevamente a Francia, ya había escrito para sí, y comenzó a publicar sus primeros relatos en la revista francesa $L a$ vie latine (Ballesteros Rosas, 1994, p. 114), con el seudónimo Frou-Frou (o Fru-Frú). Asimismo, por esta época, publicó, en el diario caraqueño El Universal, "Un evangelio indio: Buda y la leprosa" y "Flor de loto: una leyenda japonesa", ambos relatos, inspirados en culturas orientales, exploran la vida de Siddharta Gautama, el budismo, y la cultura nipona.

De la misma manera, Ana Teresa concentró su tiempo en leer a escritores franceses, Anatole France, Alphonse Daudet, Guy de Maupassant, Catulle Méndes y Romain Rollan; y al español Ramón del Valle-Inclán, quienes ejercieron una importante influencia literaria (Mueller, 2012, p. 5). Igualmente, escribió algunos cuentos fantásticos, era exigente consigo misma y decidió no publicarlos. Más tarde, apareció "Diario de una caraqueña por el Lejano Oriente", en la revista Actualidades, que dirigía don Rómulo Gallegos. Para su escritura, la autora utilizó como inspiración los viajes de su hermana María por Japón, China y Manchuria, transformó las cartas que le había enviado en narraciones ingeniosas de amena lectura.

En 1921, el príncipe Fernando de Baviera y Borbón visitó Venezuela. La ocasión fue motivo de relevantes actos protocolarios: cívicos, militares y culturales. En uno de ellos, Ana Teresa brindó el discurso de respuesta al mensaje de doña Paz de Borbón sobre la mujer, discurso que fue recibido con satisfacción por la prensa, publicado bajo el título: "La madre de España", y el cual sumó más elogios al nombre de la dama caraqueña.

En el transcurso de 1922, con el nombre Teresa de la Parra ${ }^{6}$, la autora publicó Diario de una señorita

6 No se sabe con exactitud el motivo del cambio de nombre, pero la variación guarda correspondencia con el original. Probablemente, la conservación de su "Teresa" haya sido influenciada por la tradición familiar, su tatarabuela fue doña Teresa de Jerez de Aristiguieta, prima de Bolívar y madre de Carlos Soublette, además de su inspiradora de infancia, Santa Teresa, a la cual leyó con devoción. 
que se fastidiaba, en La Lectura Semanal. El personaje de María Eugenia apareció por primera vez en esta publicación; que le merecería a la escritora el primer premio del Concurso de Novelistas Hispanoamericanos. Luego, con el cuento "La mamá X”, ganó el premio especial extraordinario en el Certamen Nacional celebrado en Ciudad Bolívar (1923). Estos primeros reconocimientos dentro del mundo intelectual local, la motivaron a emprender la publicación completa de la novela, con este propósito viajó a París en 1923, junto con su amiga doña Emilia Urbaneja, para realizar las gestiones editoriales.

\section{Teresa y el retrato de la mujer en Ifigenia (1924)}

Ifigenia $^{7}$ fue el nombre escogido por Teresa de la Parra como título de su primera novela, este tiene su origen en la mitología griega (Iphigeneia), cuyo significado es "mujer de raza fuerte". El Diario de una señorita que escribió porque se fastidiaba nació espontáneamente de las experiencias vividas por Teresa tras su regreso a Caracas y sus vivencias entre los años 1909 a 1919, aproximadamente, en los que se aburría de los eventos sociales y en cambio prefería la libertad creativa de la lectura y las conversaciones cultas con un toque de humor sutil, sarcástico e irónico, rasgos frecuentes en el desarrollo de la novela.

Asimismo, Teresa perfeccionó una predilección por los diarios, escribir sus impresiones, y reunir sus opiniones contenidas en epistolarios con amigos cercanos. Posiblemente, este hábito usual en ella la condujo a escribir por vocación personal y con un estilo del lenguaje libre, suelto, envolvente y creativo, que siempre guarda una elegancia, sutileza e inteligencia dentro del texto. Teresa escribió Ifigenia, probablemente, entre 1919 y 1922; entre la ciudad, en el valle de Caracas y la población de Macuto, la cual está ubicada en medio del verdor de las imponentes montañas y el azul del Caribe.

7 Ifigenia era hija del rey Agamenón y Clitemnestra. Según la versión más extendida del mito, la flota aquea, durante la guerra de Troya, se encontraba inmovilizada en el mar por la cólera de Artemis, Agamenón debió ofrendar en sacrificio a su hija para apaciguar a la diosa (Grimal, 1981, p. 284).
Primero de forma espontánea, influenciada por las lecturas de autores españoles y franceses, luego fue tomando sus contornos propios, delineados por sí misma, a medida que avanzaba María Eugenia y su mundo ante los ojos de Teresa.

Ifigenia presenta la búsqueda de una joven, María Eugenia Alonso, que intenta buscarse a sí misma. Es la historia de una dama que vive entre dos mundos: el europeo, de su formación, de su admiración, de su contemplación; y el americano, el local, el criollo, que percibe con asombro, con intención de comprender pero que apenas vislumbra, un mundo en el que se siente extranjera en su propio país.

En la novela se encuentran cartas y diarios con estilos muy personales, narraciones en primera persona, de lenguaje cautivador, fresco, jovial, con humor e ironía, que envuelve al lector en la personalidad de una joven de inteligencia inquieta y viva. El ambiente familiar, y social en general, cercano a María Eugenia, le lleva una y otra vez a "encajar" en la imagen "decente", predispuesta para las señoritas "de bien", de su estatus. Constantemente, su abuelita, tía Clara y tío Eduardo se lo recuerdan como designio establecido.

París es la ciudad luz, el centro cultural del mundo, espacio donde el refinamiento de las más elevadas sensibilidades artísticas y aspiraciones intelectuales han alcanzado refugio; por ello, las luces parisinas de la Belle Époque todavía irradian su esplendor magnético sobre todo el mundo latinoamericano, los reflejos de las artes a orillas del Sena colman las mentes de miles de latinoamericanos, bien sea por viajes, estadías o lecturas ávidas sobre Le Ville que cobijó a tantos literatos, inspira y fomenta una efervescencia por alcanzar los logros del Viejo Continente.

A comienzo de los años veinte, llega a Caracas la joven María Eugenia Alonso, proveniente de Europa, donde había sido educada, tras una larga estadía en Francia. María Eugenia es muy hermosa, inteligente y jovial, acostumbrada a la lectura de autores españoles y franceses, de gusto por la música, de hecho, toca el piano con destreza admirable, le agradan las 
tertulias de temas artísticos e intelectuales, el cine, el teatro y la cultura universal europea.

Escribe María Eugenia a Cristina: "Este fastidio cruel que presentí por vez primera la tarde de mi llegada, este fastidio que me ha hecho analista expansiva y escritora, tiene una raíz muy honda" (Parra, 2005, I, p. 84). Al llegar a la ciudad de Caracas, María Eugenia se encuentra con las costumbres de la alta sociedad venezolana: las continuas reuniones sociales, la devoción religiosa, la tradición familiar, la subordinación de la mujer al hombre - bien sea al padre o al marido-, la rigidez y limitación que imponen la rutina, la atención a la cocina, al bordado, en fin, todos los comportamientos esperados de señorita "decente". A lo anterior se sumó la situación económica limitada en que se hallaba, pues había quedado sin herencia debido a que su tío Antonio se quedó con la propiedad completa de la Hacienda de San Nicolás, que en vida había compartió con el padre de María Eugenia.

María Eugenia experimenta, una y otra vez, la dualidad que representa su admiración por Europa con el lugar que ocupa la mujer en la sociedad caraqueña. Ella vive en Caracas pero sus pensamientos están en París. María Eugenia intenta agradar a su abuela y comportarse de acuerdo con la tradición hispánica, pero esto choca con sus inquietudes intelectuales, culturales y artísticas, marcadas por la influencia francesa. Ella gusta de tocar piano pero no puede hacerlo en la casa familiar por guardar el largo periodo de luto debido al fallecimiento de su padre. Gusta de leer novelas y de la moda parisina, pero esto no es comprendido por el catolicismo y austeridad de las mujeres caraqueñas; en el mundo familiar, la mujer no debe aspirar a un espíritu elevado, sino que debe preocuparse por el hogar y por su marido.

Por otro lado, los únicos y breves espacios de desosiego que podía obtener María Eugenia eran con su querido tío Pancho, hombre culto que había viajado por Europa y dispensaba para su sobrina la mayor comprensión. Junto a él, doña Mercedes Galindo, dama que compartía las mismas aspiraciones de elevación cultural de María Eugenia, y don Gabriel
Olmedo, médico y abogado, de quien gusta la joven. Sin embargo, esos serán cortos momentos de compartir alguna tertulia y que no llegaron a brindar mayores satisfacciones, puesto que el matrimonio de Olmedo y la muerte del tío Pancho dejaron hondo pesar en María Eugenia, ya sumida en el fastidio de la monotonía criolla y en la tristeza del ambiente.

Ante esta situación, sorpresiva y perpleja, María Eugenia se siente encapsulada, en una conversación con su tío Pancho, le dice:

¡Si al menos hubiera nacido hombre! Verías tú, tío Pancho, cómo me divertiría y el caso que haría entonces de Abuelita y de tía Clara. Pero soy mujer ¡ay, ay, ay! Y ser mujer es lo mismo que ser canario o jilguero. Te encierran en una jaula, te cuidan, te dan de comer y no te dejan salir; mientras los demás andan alegres y volando por todas partes. ¡Qué horror es ser mujer! ¡qué horror, qué horror! (Parra, 2005, I, p. 137)

Su inconformidad la lleva a cuestionar el lugar que ocupan muchas mujeres en la sociedad, carentes de opiniones y de decisiones sobre su vida. María Eugenia expresa sus ideas, lee continuamente, argumenta, e intenta escribir. No obstante, las limitaciones de su entorno le impiden avanzar. En otra ocasión, exclamó:

¡Ah! ¡si tía Clara supiera por ejemplo, que estoy leyendo ahora el Diccionario Filosófico de Voltaire! ¿Qué escándalo y qué horror le causaría! Pero mis lecturas tienen el doble encanto de lo delicioso y lo prohibido, y el Diccionario Filosófico, cuando no está entre mis manos yace enterrado como un tesoro en el doble fondo de mi armario de espejo.

(Parra, 2005, I, p. 150)

Así, su abuela, doña Eugenia, decide que María Eugenia pase una larga temporada en la Hacienda de San Nicolás, en las afueras de Caracas. El ambiente campestre es un nuevo choque para María Eugenia: se encuentra en la hacienda que había sido de su padre, y que ahora no le pertenece, además del aislamiento de la vida en el campo, allí no parece haber lugar para la admiración por la cultura francesa. Solo el encuentro con la naturaleza, la belleza del paisaje y las aguas del río, hacen olvidar, por instantes, los 
infortunios y molestias que encierra María Eugenia en su vida caraqueña.

Hay un sentimiento de inconformidad en María Eugenia, entre lo que ella quiere y el exterior, hay una búsqueda por encontrar su identidad y su espacio, por ser ella misma. Por ello, frecuentemente, se ve al espejo, para intentar hallar lo que hay en sus ojos, lo que ella es, y quien es; a veces pudiese parecer ser algo superficial y frívola, pero esconde algo mucho más profundo, el intento de sentirse bien consigo misma, de encontrar armonía entre sus inquietudes intelectuales europeas y lo que el medio local le ofrece, quiere que haya espacios de cultura que pueda compartir en el país.

Así, en la medida que María Eugenia se siente cada vez más prisionera de su posición en Caracas, bajo la presión familiar y las limitaciones que supone no tener una propiedad o fuente de ingresos propios, debe ir cada vez más adaptándose a la condición de dejarse guiar por los cánones sociales y la influencia de sus parientes. Sus aspiraciones y anhelos intelectuales deben dejarse de lado, para dar paso a la aceptación del matrimonio, sin importar los sentimientos. Debe reducirse a sí misma para "encajar" en las proyecciones de su abuela doña Eugenia, su tía Clara y su tío Antonio, de que ella obtenga un buen marido, que le brinde el bienestar económico al que está acostumbrada, pero sin ser ella, sino solo la esposa que acompaña al marido.

\section{Dice María Eugenia:}

¡Sí! Como en la tragedia antigua soy Ifigenia: navegando estamos en plenos vientos adversos, $y$ para salvar este barco del mundo que tripulado por no sé quién, corre a saciar sus odios no sé dónde, es necesario que entregue en holocausto mi dócil cuerpo de esclava marcado con los hierros de muchos siglos de servidumbre. Sólo él puede apagar las iras de ese dios de todos los hombres, en el cual yo no creo y del cual nada espero. Deidad terrible y ancestral; Monstruo Sagrado de siete cabezas que llaman: sociedad, familia, honor, religión, moral, deber, convenciones, principios. Divinidad omnipotente que tiene por cuerpo el egoísmo feroz de los hombres: jinsaciable Moloch, sediento de sangre virgen en cuyo bárbaro altar se inmolan a millones de doncellas!... (Parra, 2005, II, p. 281)

Finalmente, María Eugenia se hace ausente de sí misma, muda, callada ante los convencionalismos sociales, acepta casarse con el doctor César Leal, alto funcionario público, pero ya no es ella, ya no es la chica viva, alegre y curiosa, sino que es una mujer silenciosa, casi resignada, cuyo cuerpo permanece allí, en la casa de la familia, pero que sus sentimientos y pensamientos parecen desvanecerse, o subsumirse, en otro mundo. Ella está allí físicamente para su familia y placer del ambiente social, pero no es ella, no es la que quería ser, entiende que es Ifigenia, y que está a punto de sacrificarse, de inmolarse.

\section{Teresa, mujer y escritora (1924-1930)}

Con Ifigenia ${ }^{8}$ llegó una serie de éxitos para Teresa de la Parra9: obtuvo el premio de la Compañía Franco-Ibero-Americana, reseñas en revistas francesas, reconocimiento de escritores como Miguel de Unamuno, quien le escribió una carta, y su novela fue leída rápida y ampliamente en importantes círculos literarios y artísticos en Hispanoamérica. Asimismo, su amiga de tertulias, doña Emilia, fallecida en 1924, le había dejado una importante herencia, con la cual podía dedicarse con libertad e independencia a su vocación literaria, pudiendo vivir en Europa con comodidad. Esto fue un enorme alivio, pues en Teresa la escritura y la vida intelectual parece ser inspiración por la cultura y por expresar, y no un oficio o profesión.

En 1928, publicó Memorias de Mamá Blanca ${ }^{10}$, su segunda novela, que también evocaba las imágenes de su abuela, de sus recuerdos de Venezuela, de la familia tradicional y de la mujer. Esta publicación, al igual que su primera obra, tuvo gran aceptación

8 En 1926, en París, se publican fragmentos en francés, por ejemplo, el de Francis de Miomandre, traducido como: Journal d'une demoiselle que s'enuie.

9 Desde el punto vista literario, se han publicado importantes trabajos. En el presente se aborda desde una perspectiva histórica; no obstante, se pueden consultar: Aizenberg, 1985, pp. 539-543; Oyola, 2004, pp. 76-103; Évora, 2005, pp. 9-26; entre otros.

10 En 1929, se publicó en francés, Mémoires de Maman Blance (París: Librerie Stock); y en 1959, la edición en inglés, Mama Blanca's Souvenirs (Washington: Pan American Union). 
entre la crítica literaria y en el público hispano que la leyó, lo cual contribuyó a consagrar su reconocimiento como escritora.

Por esta época, de 1923 a 1931, Teresa comenzó una intensa vida de viajes intelectuales, constantes, motivados directamente por sus actividades literarias, que la llevaron a departir entre invitaciones, tertulias, reuniones, conferencias y encuentros familiares con sus hermanas; entre Francia, donde residía, Suiza, en la que pasaba los veranos, y España, Italia, Alemania, Venezuela, Colombia, Panamá, Cuba y Estados Unidos.

Así, residía la mayor parte en París, en la cual se dedicó a leer, a escribir, a frecuentar pequeños grupos literarios e intelectuales, principalmente de escritores y diplomáticos latinoamericanos. De este modo, Teresa de la Parra conoció y tuvo amistad con diversos escritores, como el español Unamuno, el mexicano Alfonso Reyes, los chilenos Carlos Morla Lynch y Gabriela Mistral, la cubana Lydia Cabrera, entre otros. Visitó La Habana en 1927, asistió, en calidad de invitada, al Congreso de Prensa Latina, en el cual dictó una conferencia sobre Bolívar. Al año siguiente, visitó Múnich para asistir al festival wagneriano, luego regresó a París para hacerse cargo de la traducción al francés y edición de su segunda obra.

Para 1930, en Colombia, donde su obra había alcanzado importante reconocimiento, más que en la Venezuela de la dictadura gomecista, Teresa de la Parra fue invitada a dictar una serie de conferencias tituladas: "La importancia de la mujer americana durante la Colonia, la Conquista y la Independencia" (Parra, 1961), que presentó con significativo éxito en Bogotá y Barranquilla. La prensa colombiana, y el público en general, recibieron a Teresa con efusión, como quedó registrado en los diarios bogotanos Ahora y La Tarde.

\section{La mujer en Ifigenia y su autora (1931-1936)}

Tanto en Europa como en América Latina, el siglo XIX se extendió, no en sentido cronológico sino histórico, hasta la Primera Guerra Mundial (19141918). Esto explica por qué muchos de los rasgos decimonónicos perduraron hasta las primeras décadas de la centuria veinte.

Sobre la mujer latinoamericana de comienzos de siglo, sostienen Caro y Barranco (2006) lo siguiente:

En los Estados latinoamericanos, las mujeres casadas debían permanecer casi todo el tiempo en su hogar, ya que deambular por las calles era considerado poco respetable; la ciudad era un espacio masculino y sólo los hombres gozaban de la prerrogativa de circular solos por plazas y calles, sin ser censurados. Las narrativas y plásticas de la época recreaban esa geografía urbana de género; refrendando el ideal domestico femenino al representar a las mujeres blancas en interiores o en jardines. (p. 552)

Si bien muchas mujeres, tanto del siglo xix como del $\mathrm{xx}$, debían trabajar largas jornadas para el sustento de sus hogares, este no era el caso de las damas de la cima social, quienes habían logrado, desde fines de la centuria, mayores espacios, aún incipientes, en la educación formal, escasamente en la universitaria, y se habían atrevido a organizar salones de tertulias, asociaciones benéficas, primeras experiencias editoriales con revistas, relatos, novelas, versos, como la argentina Juana Gorriti (1818-1892), la chilena Martina Barros (1850-1944), la peruana Clorinda Matto (1852-1909), entre otras. Sin embargo, en la sociedad predominaba aún la articulación del ámbito familiar, en el interior de las casas, lo imponía la religión y el matrimonio, es este uno de los tópicos que recoge Ifigenia.

En especial, sobre esta relación de la mujer con la tradición familiar y el matrimonio, señala Guerra Cunningham (2004):

Debido a la ausencia de posibilidades ofrecidas por la sociedad patriarcal a la mujer de la década de los años veinte, a María Eugenia no le queda otra alternativa que ser absorbida por ese orden. Su trayectoria, lejos de poseer un carácter teleológico de evolución, ha sido un girar y regirar en las restringidas modalidades de la condición de ser mujer. Por lo tanto, las imágenes literarias de Julieta, la Cenicienta, la pastora de Perrault, Penélope e Ifigenia reiteran la ficción de la felicidad y la tragedia como único desenlace posible. (p. 138) 
Como bien expresa Guerra Cunningham, proponiéndoselo o no, la voz femenina discurre libremente hacia la comunicación de inconformidad ante las pocas, o ninguna, oportunidades de la mujer de poder ser independiente, económica y personalmente, en la toma de decisiones sobre su destino. Por ello, dentro de Ifigenia, está nítidamente impreso el desconcierto de la identidad propia de una señorita, que se busca a sí misma, y que debe, al final, sacrificarse, suprimirse, para adaptarse en el concierto social de la familia de sociedad.

Por su parte, señala Acker (1988):

Filosóficamente, Teresa de la Parra presenta sonidos e ideas atractivas, práctica, estética y, a menudo originales. Que ella sea elogiada y clasificada como una escritora de tradición europea es difícil de entender. ¿Es por su dicción impecable, elegante uso del lenguaje y el equilibrio clásico? Sus temas son estadounidenses. Seguramente Estados Unidos no desearía rechazarla por la belleza de su estilo fluido. ${ }^{11}$ (p. 76)

Para Acker, Teresa de la Parra, en un sentido filosófico - e histórico-, logra reunir en sí misma ese rasgo que lleva consigo su María Eugenia, esa dualidad entre el mundo europeo y americano, plasmada en la obra de Teresa, en la que reunen espontáneamente su formación intelectual y cultural europea. Su estilo y visión son europeos, pero su escenario transcurre en suelo americano, y su tema central, la mujer y sus ideas, es universal.

Ifigenia recoge muchos aspectos autobiográficos de su autora, Teresa de la Parra, presentados con un matiz de humor irónico y estilo novelado. Su María Eugenia tiene, naturalmente, mucho de Teresa, pero a la vez mucho de muchas mujeres latinoamericanas, que en ocasiones se abstuvieron o callaron ideas y opiniones como las de María Eugenia, frente a las costumbres enraizadas de supresión de la voluntad

11 "Philosophically, Teresa de la Parra presents sound and appealing ideas, practical, esthetic and often original. That she is both praised and be rated as a writer in the European tradition is more difficult to understand. Is it because of her flawless diction, elegant use of language and classical balance? Her themes are American. Surely America would not wish to reject her for the fluid beauty of her style" (Traducción elaborada para el presente artículo). femenina, algo común en buena parte del mundo iberoamericano. María Eugenia, con toda su inteligente ocurrencia y gracia juvenil, se convirtió en la heroína de lectoras que, a principios del siglo $\mathrm{xx}$, veían en sus páginas las recreaciones de situaciones similares a las suyas, especialmente porque esta joven americana sabía argumentar, gustaba de los avances de la cultura y reunía la sensibilidad de la razón y los sentimientos artísticos.

De la Parra, de acuerdo con Araújo (1982, p. 27), abre una etapa en la narrativa latinoamericana femenina, presentando el tema de cómo se siente la mujer dentro del ámbito familiar. A esta obra adelantada, Ifigenia, le siguieron otras como La amortajada (1941), de la chilena María Luisa Bombal, publicada en Buenos Aires en 1938, que retrata la situación de la dama en su relación con la sociedad patriarcal, tutelada por el hombre. Después, la venezolana Antonia Palacios editó su Ana Isabel, una niña decente (Palacios, 1949), en la que recogió los recuerdos de educación de una jovencita en los cánones que le correspondía, como niña de bien. Todo esto se circunscribe dentro de una necesidad, una aspiración a decir y expresar lo que vivían y pensaban las mujeres latinoamericanas de la primera mitad del siglo $\mathrm{xx}$.

En opinión de Zapata (1975):

A diferencia de muchas mujeres escritoras que han leído sin digerir y no pueden escapar de un tono intimista y confesional, Teresa de la Parra demuestra una madurez de estilo y una sobria separación entre ella como autora y su trabajo como un acto creativo. La distinción entre "femenino" y "masculino" en su literatura desaparece cuando se refiere al estilo de esta destacada escritora. ${ }^{12}$ (pp. 13-14)

En cuanto al estilo y el lenguaje de la obra, de acuerdo con Zapata, en Teresa de la Parra se puede

12 "In contrast to many women writers who have read without digesting and cannot escape an intimate and confessional tone, Teresa de la Parra demonstrates a maturity of style and a sober separation between herself as an author and her work as a creative act. The distinction between 'feminine' and 'masculine' literature disappears when this prominent writer's style is concerned" (Traducción elaborada para el presente artículo). 
observar una armonía de lo íntimo, personal, confidencial, de una jovencita caraqueña educada en Europa, con todo un público amplio, tanto masculino como femenino, que sigue la vida de María Eugenia, no como a una joven dama, sino como la de muchas damas que se identifican en ella, y con toda una sociedad que las rodea. La autora logra, con inteligencia, creatividad y sutileza, unir empatía y simpatía en las respuestas de María Eugenia, las cuales generan, en hombres y mujeres, sorpresa y curiosidad (Zapata, 1975). Sus palabras son genuinas, cultivadas y denotan una amplia lectura universal, siempre tienen una pisca elegante de humor, de sarcasmo, de ironía ante la vida; cada idea suya es espontánea y sincera, no ingenua ni predecible.

Por su lado, Truneanu Castillo (2005) expresa lo siguiente:

[...] Teresa de la Parra fue una mujer de ideas avanzadas para su época. En sus conferencias ya predijo y propuso lo que sería la verdadera liberación femenina, conquistada a través del trabajo y los estudios, de modo que ella fue una visionaria en cuanto al rol de las mujeres. Al mismo tiempo, en su novela Ifigenia, [...] Se muestra al personaje de María Eugenia Alonso como una mujer que quiere luchar por esa liberación y que tiene unas ideas muy propias. Esta singularidad de ideas ve su reflejo en el discurso, ya que el mismo lenguaje de María Eugenia se diferencia del que emplean los demás personajes. (p. 137)

De acuerdo con esta autora, en el trabajo intelectual de la escritora y de su obra, se presentan muestras de un feminismo ${ }^{13}$ moderado, tendiente a que la mujer pueda preocuparse por leer, por educarse, por dedicarse a las artes o a las letras. Teresa de la Parra trata de presentar una mujer que puede decidir, actuar y participar en la vida, no por simple belleza o capricho, sino por ser una mujer pensante, una mujer que cultiva su inteligencia. En este sentido, María Eugenia es la expresión de la mujer

13 Naomi Lindstrom, en su "Introduction", opina: "The author had witnessed the spread of feminism in European intellectual circle and had considered how this movement might apply to the Spanish American context, particularly among women who had little if any change to study progressive social thought" (Parra, 1993). preocupada por cultivarse a sí misma, por nutrirse de todo lo que el mundo intelectual puede ofrecerle: podía leer en tres idiomas, leía a Dantes, Cervantes, Fray Luis de León, Shakespeare, Rostand, Voltaire, José Asunción Silva, Schopenhauer, Eurípides, entre otros. Muy posiblemente, lecturas cultivadas por de la Parra.

Teresa siempre conservó una belleza y juventud resaltante, ya para comienzos de los años treinta había cumplido cuatro décadas de vida, sin embargo, su rostro le hacía ver mucho más joven, como una dama eternamente elegante, de conversación culta, como si nunca hubiese sobrepasado los treinta años. Probablemente, su mismo carácter mesurado y actitud serena contribuían a esa imagen. Luego de sus viajes por América, Teresa volvió a Europa. Cada vez más evadía invitaciones y reuniones, se encerró en lecturas sobre la historia de Venezuela, la herencia hispánica en América, biografías sobre su admirado Bolívar, historia de la filosofía, poesía alemana, Hölderlin, Rilke, y estudios orientales, en especial, el budismo y el misticismo oriental.

Asimismo, Teresa se enteró de su enfermedad ${ }^{14}$, tuberculosis, lo cual le impactó sensiblemente, y la hizo asumir tal realidad como un destino que entremezcla lo romántico y lo trágico, quizá, la misma influencia de sus lecturas la llevaron a interiorizar más la situación, afrontarla como una muerte que está allí, cercana, esperándola. Se internó en el Grand Hotel de Leysin, Suiza, donde residió largas temporadas, en busca de alivio. En su último lustro de vida, se volvió más solitaria, mantuvo comunicación con pocos amigos. Sus recuerdos de infancia y reflexiones se hicieron explicativos de una búsqueda interior, leía a Freud y el psicoanálisis. Recordaba que Bolívar también había muerto de tuberculosis.

A la par del conocimiento de su enfermedad, inició la escritura de un diario personal desde 1931, en el que expresó todas sus angustias y reflexiones. Con

14 Sobre la mujer y la enfermedad a comienzos del siglo xx, resulta interesante contrastar el testimonio de Teresa de la Parra recogido en su "Diario de Bellevue - Fuenfría - Madrid, 1931-1936", publicado en su Obra (1982), con los testimonios de Lily Iñiguez (1902-1926), 1954; y Lucía Manterola (1903-1927), 2011. De hecho, tanto Lily como Teresa acudieron a Leysin, Suiza, en busca de tratamiento. 
el pasar del tiempo, sus ánimos variaron: en 1932, ahondó en su búsqueda interior; hacia 1933, se volvió optimista, en espera de pronta y positiva curación; en 1934, se presentó una bronquitis asmática; al año siguiente, viajó a París, y finalmente a España. Teresa murió en Madrid el 23 de abril de 1936 ${ }^{15}$.

\section{Teresa, Ifigenia y el tiempo (trascendencia en el siglo $\mathrm{xx}$ )}

Al poco tiempo de su ausencia física, escribió Miró (1936) lo siguiente:

Teresa de la Parra era una de las mejores escritoras actuales de habla española. Y al decir esto se debe entender que esas escritoras son contadísimas. $\mathrm{Mi}$ clasificación es estricta y por eso la incluyo en ella. Cuando nos referimos a un escritor preferido, no debemos hallarlo sino en su constreñida elite, en ese difícilmente asequible Eliseo tan lejano de lo académico, de lo conocido oficialmente. Se me dirá que la obra de Teresa de la Parra fué leída con cariño y se le concedió honores de primer premio, etc. Esto es secundario para mí. Yo la veo en ese plano de las escasas escritoras españolas o hispano-americanas, en esa minoría literaria de un valor positivo, incomparable fuera de su órbita. (p. 35)

La muerte de Teresa, cuando era todavía una dama joven, le impidió culminar otros proyectos intelectuales. Sus éxitos editoriales (Ifigenia y Memorias de Mamá Blanca) le han sobrepasado en fama a ella misma, su segunda novela se colocó sobre la primera y sobre su autora, debido a sus críticos literarios - quizá con el auspicio de Teresa-. En vida, de la Parra fue muy conocida dentro de los círculos literarios hispanoamericanos de Francia, España y América; su camino ha sido, como otras figuras de las letras americanas, de espacios de elevación y otros de decaimiento; probablemente influya en esto cuánto se leen a sí mismos los latinoamericanos.

La universalidad de la obra de Teresa se expresa en diversas formas. Su propio nombre, Ifigenia,

15 Curiosamente, el mismo día que en 1616, murieron Miguel de Cervantes y William Shakespeare. rememora, al instante, la herencia helénica con su rica mitología y el sacrificio que recoge el episodio del mito. Se suma a ello los rasgos culturales hispánicos heredados de los antepasados, vínculos comunes desde el sur del río Bravo, en México, hasta Punta Arenas, en Chile, pasando por el norte, centro y sur de América, donde se funde el idioma castellano, la religión católica, la tradición de sociedades patriarcales, entre otras. Por esto se hacen tan cercanos los avatares diarios que fastidian a María Eugenia con los de centenares - quizás miles- de jovencitas latinoamericanas en igual posición.

Por otro lado, María Eugenia se conecta con las familias principales de las grandes ciudades latinoamericanas, que pueden acceder a educarse en Europa, principalmente en Francia, cuya luz, tal cual Faro de Alejandría, continuaba proyectándose sobre l'Amerique latine, a principios del siglo $\mathrm{xx}$, como lo había hecho en la centuria pasada, lo que conecta, aún más, las realidades que se tocan, que fluctúan, entre la joven caraqueña y una señorita santiaguina, y otra bonaerense, porque por igual sus ojos y mentes veían al Viejo Mundo como el modelo a seguir.

Asimismo, la influencia francesa en toda América Latina se puede observar en distintos espacios de la vida cultural del continente. A principios del siglo xx, el chileno Luis Orrego Luco plasmó en su novela, Casa Grande (1908), el mismo tema de la tradición, de las familias principales, el matrimonio, y la referencia gala al medio americano:

Eso no se ve en París. Cuando me acuerdo del Moulin Rouge o del Palais de Glace, me dan ganas de volverme a Europa en el próximo vapor. ¡Ah!... Sí... Esos sí que son trajes los que se ponen esas damas, y iqué brillantes!, y iqué pieles, Señor mío, las que gasta! (p. 15)

De este modo, se puede apreciar cómo a lo largo y ancho de América Latina, desde Santiago a Caracas, y demás capitales americanas, el mundo cultural giraba en torno a Francia, las artes, la pintura, la escultura, la literatura, la moda, los cosméticos. Por ello, tanto en Casa Grande como en Ifigenia, todo lo francés se hace siempre presente en los gustos y eventos de las sociedades santiaguina y caraqueña. 
Contemporáneo a los procesos del siglo $\mathrm{xx}$, Picón-Salas (1983) dice:

Muchas mujeres hispanoamericanas, prisioneras todavía en las más ñoñas rutinas y convenciones, estaban esperando un mensaje semejante. E Ifigenia, obra única por su gracia y su adolescente malicia que no es sino la más pura forma poética del candor, conquistó todo el mundo hispánico. Se leía, simultáneamente, en México, en Bogotá, en Montevideo, en Santiago de Chile. Conocí un viejo profesor chileno de Filosofía que me confesaba como un pecado deleitoso haber dedicado a la pequeña y fantástica María Eugenia Alonso un tiempo robado a Kant. (p. 135)

El pensador merideño recogió parte de la audiencia e impresión generada por la obra de Teresa de la Parra, al dejar testimonio de la lectura de Ifigenia en América Latina, e incluso, contar con tono anecdótico el alcance de la novela en los elevados círculos académicos. Ello es una muestra de la recepción que había obtenido dentro del público americano la obra de Teresa, que alcanzó una importante extensión del continente hispanoparlante, gran cantidad de féminas y espacios cultos.

De igual manera, reflexiona Uslar-Pietri (1996) lo siguiente:

Teresa de la Parra es una de las escritoras más femeninas. Nadie la excede en este don. Ifigenia es un libro mujer: atractivo, oscuro, turbador.

Es una larga y divagante confidencia de un alma profundamente femenina. Ve, habla, describe y piensa como nunca podía hacerlo un hombre. En su prosa hay frases, torpezas, simples adjetivos, que son como una incitadora desnudez. (p. 397)

Uslar-Pietri meditaba que ningún hombre podía alcanzar la sensibilidad de lo escrito por Teresa y su Ifigenia. El mundo femenino que logró retratar, lo autobiográfico, individual y colectivo, a través de cartas de María Eugenia a Cristina de Iturbe, de registro personal de un diario o, simplemente, en descripciones en primera persona, aportan a la obra de Teresa un matiz innovador, original, único, que combina la introspección femenina con el exterior social, regido por lo masculino, supera lo criollo, lo local, el relieve natural, para acercarse a la palabra y decisión de la mujer, lo que piensan, lo que opinan, lo que aspiran en sus vidas las damas.

Asimismo, del todavía modesto grupo de mujeres americanas que incursionaban en la escritura a comienzos del siglo xx, sobresalió la chilena doña Inés Echeverría Bello (1868-1949), descendiente de don Andrés Bello, quien tomó el nombre de "Iris" para firmar muchos de sus trabajos. Hay varios e interesantes rasgos coincidentes entre doña Inés y Teresa, que no solo acercan sus producciones literarias, sino también, en buena parte, su cosmovisión del mundo.

En este orden, las familias principales latinoamericanas que podían hacerlo enviaban a sus hijos, niñas o varones, a Europa en viajes de formación, "baños de cultura". Casos por igual, ambas damas, Inés y Teresa, se habían educado en el Viejo Continente, y muy especialmente en Francia. Doña Inés había nacido en Santiago de Chile en 1868. Hacia 1888 cruzó el Atlántico, en 1889 asistió a la Exposición Mundial de París, el mismo año y en la misma ciudad que nació Teresa. No obstante su matrimonio y el nacimiento de sus hijas, doña Inés tuvo ocasión de viajar extensamente y escribir. Ya para 1905, aparecieron sus primeras publicaciones, una de ellas es "Hacia el oriente", en la que se evidencia su inquietud por el mundo del Lejano Oriente, tema que aparece también en Teresa, con sus publicaciones sobre Buda y el Japón.

Asimismo, doña Inés publicó su Memoria de Iris 1899-1925 (Echeverría Bello, 2005) en la década de los veinte, mismo periodo en que Teresa editó Ifigenia. Diario de una señorita... En ambas obras sobresalen dos aspectos importantes: los diarios y Europa-América. El primero, los diarios personales como instrumentos primarios, fuente rica de reflexión y meditaciones de impresiones vividas, de viajes y acontecimientos, que permiten dialogar consigo mismo; el segundo, la constante referencia de Europa y las circunstancias americanas, que, al final, terminan fundiéndose en una misma, en una fluctuación europeo-criollo, es decir, sus pensamientos y 
miradas están en Europa, y muy particularmente en Francia, mientras, a la vez, tropiezan y conviven con el escenario americano, lo local hispanoamericano. Esta preocupación del mundo europeo-americano representa una búsqueda de identidad del ser y esencia humana, porque en los salones de Europa, los nacidos en América eran suramericanos y nunca europeos; y en las ciudades americanas, eran criollos que se sentían extranjeros.

\section{Consideraciones finales}

El quehacer literario de las damas latinoamericanas pioneras en el mundo de la escritura recobra una dimensión mayor, al constituirse en aportes significativos en la comprensión global, integral, del devenir americano. Son estas fuentes complementarias, sin desmerecer su naturaleza lírica, en todo un conjunto de descripciones de escenarios naturales, ambientes urbanos, medios rurales, costumbres religiosas, convencionalismos sociales, el relato se desarrolla en Caracas pero puede hallarse matices de Latinoamérica, todo lo cual lleva a responder el rompecabezas de ¿cómo pensaban las mujeres de principios del siglo $\mathrm{xx}$ ?, ¿por qué actuaban de una u otra manera?, ¿hasta qué punto influía la Europa en el día a día hispanoamericano?, entre muchas otras interrogantes, que con fuentes históricas tradicionales, políticas u oficiales, sería más que difícil explorar.

Ifigenia, sin dejar de ser una memoria novelada, tiene un aporte testimonial que permite acercarse a las aspiraciones y frustraciones de las jóvenes damas en la sociedad, de ahondar dentro del mundo complejo de la psique humana, que, más allá de la aparente superficialidad y frivolidad de su protagonista, recoge una profunda preocupación de búsqueda de identidad, de ser partícipe en la toma de decisiones en la sociedad, y por extensión de las naciones americanas. Convergen en María Eugenia la vivencia individual, que a su vez se vuelve colectiva, de miles de jovencitas latinoamericanas, capaces de opinar y sustentar sus argumentos.
Los retratos de la mujer que se presentan en Ifigenia poseen un carácter americano, una dualidad intrínseca europea-criolla, que se refleja en todos los personajes femeninos de la obra: la abuelita doña Eugenia reúne en sí la tradición hispánica; la tía Clara, la abstinencia y resignación; doña Mercedes Galindo, la admiración por el mundo intelectual que se ha reprimido a sí misma por ocasión del adaptarse al matrimonio, dejando todo su anhelo de lado; y María Eugenia descubre, tristemente para ella, que al final debe sacrificarse a sí misma para la complacencia exterior. Ifigenia es la obra de una mujer que deja atrás el romanticismo decimonónico y el paisajismo que había impregnado la literatura masculina hasta ese momento.

Finalmente, es Teresa de la Parra una de las damas americanas cuya efímera vida legó dos obras relevantes para la mayor comprensión de la mujer latinoamericana, y de alcance universal, no solo por el valor literario de las mismas, sino también por su propia actuación como escritora e intelectual, que erigió su trabajo en forma de relatos (cortos y fantásticos), de novelas originales, y de conferencias de preocupación sobre el lugar de las mujeres en la nación. Su vida y su obra, de importante contenido autobiográfico, tienen pleno valor en el siglo XXI, no por ser una de las pioneras en la escritura, no por haber sido una dama educada y culta - que ya de por sí la hace sobresalir en su época-, sino por el auténtico esfuerzo por escribir con propiedad, por haber comunicado algo original, de manera creativa, por haber realizado lo que pensaba. Más allá del éxito artístico de sus obras, es necesario redescubrir la dimensión genuina de su trabajo.

\section{Referencias}

Acker, B. (1988). Ifigenia: Teresa de la Parra’s social protest. Letras Femeninas, 14, 1/2.

Aizenberg, E. (1985). El bildungsroman fracasado en Latinoamérica: el caso de Ifigenia de Teresa de la Parra. Revista Iberoamericana, 51, 132-133.

Araújo, H. (1982). Narrativa femenina latinoamericana. Hispanoamérica, 11, 32. 
Ballesteros Rosas, L. (1994). La escritora en la sociedad latinoamericana. Cali: Universidad del Valle.

Barros, M. (1942). Recuerdos de mi vida. Santiago: Orbe.

Bombal, M. L. (1941). La amortajada (segunda edición). Santiago: Nascimento.

Bosch, V. (1979). Esta pobre lengua rica: relectura de la obra de Teresa de la Parra. Caracas: Presidencia de la República.

Caro, G. y D. Barranco (2006). [Introducción]. En I. Morant (Dir.), Historia de las mujeres en España y América Latina. Del siglo XIX a los umbrales del siglo XX. Madrid: Cátedra.

Díaz Sánchez, R. (1954). Teresa de la Parra. Clave para una interpretación. Caracas: Garrido.

Echeverría Bello, I. (2005). Memorias de Iris. 1899-1925. Santiago: Aguilar.

Évora, C. (2005). Imagen y territorialidad de lo femenino en Ifigenia de Teresa de la Parra. Lengua y Habla, 9.

Gorriti, J. M. (2006). Peregrinaciones de un alma triste. Buenos Aires: Stockcero.

Grimal, P. (1981). Diccionario de mitología griega y romana. Barcelona: Paidós.

Guerra Cunningham, L. (2004). Cuerpo de mujer y rituales del adorno en Ifigenia de Teresa de la Parra. Letras Femeninas, 30, 1.

Iñiguez, L. (1954). Páginas de un diario. Santiago: Editorial del Pacífico.

Lemaitre, L. A. (1987). Mujer ingenia. Vida de Teresa de la Parra. Madrid: La Muralla.

Manterola, L. (2011). Diario de una joven tuberculosis. Santiago: Ministerio de Salud Chile.

Matto de Turner, C. (1994). Aves sin nido. Caracas: Biblioteca Ayacucho.

Miró, C. (1936). Teresa de la Parra. Revista Hispánica Moderna, 3, 1.
Mueller, R. A. (2012). Teresa de la Parra. A Literary Life. Newcastle: Cambridge Scholars Publishing.

Orrego Luco, L. (2005). Casa Grande. Escenas de la vida en Chile. Caracas: Biblioteca Ayacucho.

Oyola, G. (2004). Abrirme el alma con la pluma. Notas sobre Ifigenia de Teresa de la Parra. Connotas, Revista de crítica y teoría literaria, 2, 2.

Palacios, A. (1949). Ana Isabel, una niña decente. Buenos Aires: Losada.

Palacios, M. F. (2005). Teresa de la Parra. Caracas: El Nacional, Banco del Caribe.

Parra de la, T. (2005). Ifigenia. Dos Tomos. Caracas: Monte Ávila.

Parra de la, T. (1993). Iphigenia. (Diary of a young lady who wrote because she was bored). Austin: University of Texas Press, 1993.

Parra de la, T. (1982). Obra (Narrativa, ensayos, cartas). Caracas: Biblioteca Ayacucho.

Parra de la, T. (1961). Tres conferencias inéditas. Caracas: Garrido.

Picón-Salas, M. (1983). Viejos y Nuevos Mundos. Caracas: Biblioteca Ayacucho.

Pino Iturrieta, E. (Coord.). (1988). Juan Vicente Gómez y su época. Caracas: Monte Ávila.

Truneanu Castillo, V. (2005). Confesiones sobre rebeldía y sacrificio: Notas sobre Ifigenia de Teresa de la Parra. Anales de Literatura Hispanoamericana, 34.

Uslar-Pietri, A. (1996). La invención de América mestiza. México: Fondo de Cultura Económica.

Zapata, C. (Spring, 1975). One hundred years of Women Writers in Latin America. Latin American Literary Review, 3, 6 . 